\title{
ENFOQUE À LEGISLAÇÃO BRASILEIRA E EUROPEIA SOBRE A INDICAÇÃO GEOGRÁFICA
}

\author{
Approach to theBrazilian and European legislation on geographical indication
}

\author{
Sabrina Cantarelli Almeida', Andréa Cristina Dörr², Jaqueline Carla Guse³, Marivane Vestena Rossato ${ }^{4}$, Katia \\ Laura Sidali ${ }^{5}$, Aldo Marchese 6 \\ 'Universidade Federal de Santa Maria (UFSM) - Mestre em Economia \\ ${ }^{2}$ Universidade Federal de Santa Maria (UFSM) - Prof. ${ }^{a}$ Adjunta do Departamento de Ciências Econômicas \\ ${ }^{3}$ Universidade Regional de Blumenau (FURB) - Mestranda em Ciências Contábeis \\ ${ }^{4}$ Universidade Federal de Santa Maria (UFSM) Prof. ${ }^{a}$ Adjunta do Departamento de Ciências Contábeis \\ ${ }^{5}$ Universidade Georg-August de Göttingen Pós-Doutoranda e pesquisadora do Departamento de Economia Agrária e Desenvolvimento \\ Rural de Comercialização de Produtos Agrícolas. \\ ¿Universidade de Bologna Doutorando em Economia dos Alimentos e Estatística pela Alma Mater Studiorum na Escola de Economia, \\ Gestão e Estatística, Departamento de Ciências Estatísticas.
}

\begin{abstract}
Resumo
A adoção da indicação geográfica (IG) está associada à tradição do conhecimento e do alimento. Tendo-se em vista que os estudos nessa temática são ainda muito recentes e escassos no Brasil, objetivou-se realizar uma revisão da literatura sobre as legislações e normatizações, existentes no Brasil e na Europa, sobre indicação geográfica. Utilizou-se o método qualitativo, através de um estudo descritivo e com utilização da pesquisa bibliográfica. Observa-se que as preocupações com indicações geográficas são mais antigas nos países da União Europeia e que a legislação europeia traz uma forte regulamentação sobre o assunto. No Brasil, essa visão trazida pela indicação geográfica ainda é muito recente e caminha para uma maior valorização e regulamentação dos produtos dessa natureza. Conclui-se que as IGs trazem contribuições extremamente positivas para as economias locais e para o dinamismo regional, proporcionando o real significado de criação de valor, atuando como uma espécie de certificação com atributos definidos e garantindo seu enquadramento às normas pré-estabelecidas. Palavras-chave: Indicação geográfica, Regulamentação, Legislação.
\end{abstract}

\begin{abstract}
The adoption of the Geographical Indication (GI) is associated with the tradition of knowledge and food. Bearing in mind that the studies on this topic are still very recent and scarce in Brazil aimed to conduct a literature review of existing law sand norms in Brazil and in Europe on the aspect of geographical indication. We used the qualitative method, through a descriptive study and using the literature search. It is observed that concerns about Geographical Indications are the oldest in the countries of the European Union, and European legislation brings strong regulation son the subject. In Brazil this vision brought by the Geographical Indication is still very recent and walks to a greater appreciation and regulation of such products. It follows GIs bring extremely positive contributions to local economies and to regional dynamics, providing the real meaning of value creation, acting as a kind of certification with defined attributes, ensuring their consistency with prescribed standards.

Keywords: Geographical indication, Regulation, Legislation.
\end{abstract}




\section{INTRODUÇÃO}

Com a concorrência no mercado de alimentos, a preocupação com a inovação e a diferenciação de produto é vista como ponto estratégico de muitas empresas. Isso ocorre pelo fato de existir um novo perfil do consumidor, que busca produtos com qualidade, descrição das suas características e origem. Valente et al. (2012) afirmam que fatores como a globalização, incertezas com relação à procedência dos alimentos e crises alimentares promovem o desejo dos consumidores em comprar produtos diferenciados, cuja qualidade e procedência possam ser garantidas.

A adoção do selo de indicação geográfica (IG) representa uma forma de inovação e de diferenciação de produtos. A IG é um dos temas que tratam da temática da Propriedade Intelectual. Essa propriedade refere-se, por determinação da World Intellectual Property Organization (WIPO), às criações humanas, tais como: invenções, obras literárias e artísticas, símbolos, nomes, imagens e desenhos utilizados para o comércio. A propriedade intelectual é dividida em duas categorias: direitos autorais, categoria que inclui obras literárias e artísticas; e propriedade industrial, que inclui patentes, marcas, desenhos industriais, indicações geográficas e de fonte (WIPO, 2013).

Segundo a Organização Mundial do Comércio (OMC), a indicação geográfica é um sinal utilizado em produtos que têm uma origem geográfica específica e possuem qualidades, reputação ou características que são essencialmente imputáveis a essa origem, de modo que torna esses produtos conhecidos por sua designação geográfica de procedência (GOLLO, 2006). Dessa forma, a IG delimita a área de produção, restringindo seu uso aos produtores da região, além de manter os padrões locais, impedindo que outras pessoas utilizem o nome da região em produtos ou serviços de forma indevida (REIS, 2008).

Indicações geográficas são ferramentas que visam à valorização de produtos tradicionais vinculados a determinados territórios. Procuram agregar valor ao produto e proteger a região produtora e sua herança histórico-cultural (GIESBRECHT et al., 2011). Essa herança deve apresentar especificidades intimamente relacionadas com sua área de produção, ter um grupo de produtores que se responsabilize pela garantia da qualidade na elaboração dos produtos e possuir um nome de reconhecida notoriedade (KAKUTA et al., 2006).

Ainda, constituem uma espécie de direito de propriedade intelectual que vem ganhando destaque desde seu reconhecimento internacional pela OMC, em 1994, com a criação do acordo Trade-Related Aspects of Intellectual Property Rights (Trips), Seção 3 (IG), Artigos 22 a 24, denominado nacionalmente como Acordo sobre Aspectos dos Direitos de Propriedade Intelectual relacionados ao Comércio (ADPIC) (NGOKKUEN e GROTE, 2012). O Brasil aderiu a esse tratado e o internalizou através do Decreto ${ }^{\circ} 1.355$, de 1994.

O acordo Trips é o primeiro acordo multilateral da OMC que exige o estabelecimento, nos sistemas legais nacionais dos países-membros, de um conjunto detalhado de normas substantivas, assim como o estabelecimento de medidas e procedimentos de execução que atendam a padrões mínimos. Ou seja, o acordo não apenas impõe obrigações ou deveres aos membros da OMC, como também concede um conjunto considerável de direitos.

Os membros têm o direito de implementar o acordo Trips da maneira que considerarem mais apropriada. Há uma grande flexibilidade inerente ao direito de Propriedade Intelectual. Os membros têm tanto o "direito" de usar a flexibilidade inerente ao acordo como a "obrigação" de cumprir seus requisitos mínimos (OMC, 1994).

Atualmente, a IG constitui um direito de propriedade intelectual autônomo reconhecido nacional e internacionalmente: no Brasil, pela Lei de Propriedade Industrial (Lei ${ }^{\circ}$ 9.279/1996) e, internacionalmente, pelo Acordo Trips, da OMC (VALENTE et al., 2012). Nesse contexto, o presente estudo teve como objetivo realizar uma revisão de literatura acerca das abordagens trazidas pelas legislações brasileiras e europeias em relação à indicação geográfica.

\section{MÉTODOS E PROCEDIMENTOS}

O estudo caracterizou-se, quanto ao objetivo exposto, como um estudo de caráter descritivo. Em relação às pesquisas descritivas, Gil (2010, p. 27) afirma que tem como objetivo "a descrição das características de determinada população. Podem ser elaboradas também com a finalidade de identificar possíveis relações entre variáveis".

No que tange à sua abordagem, em relação ao problema, foi considerado como de natureza qualitativa, devido ao fato de não ter-se preocupado com dados estatísticos ou especificamente numéricos. Sampieri et al. (2006, p. 8) afirmam que a pesquisa com enfoque qualitativo tem uma realidade a descobrir e que "busca principalmente 
dispersão ou expansão dos dados ou da informação". Ainda conforme Sampieri et al. (2006, p. 11), os estudos qualitativos "não pretendem generalizar de maneira intrínseca os resultados para populações mais amplas, nem necessariamente obter amostras representativas".

Como procedimentos técnicos, utilizou-se a pesquisa bibliográfica. Segundo Gil (2010, p. 29), a pesquisa bibliográfica "é elaborada com base em material já publicado. Tradicionalmente, esta modalidade de pesquisa inclui material impresso, como livros, revistas, jornais, teses, dissertações e anais de eventos científicos". Ou seja, ela explica um problema a partir de materiais já publicados.

\section{HISTÓRICO DA INDICAÇÃO GEOGRÁFI- CA NO MUNDO}

Ao longo da história, o conceito de indicação geográfica desenvolveu-se de forma natural, quando produtores, comerciantes e consumidores perceberam que alguns produtos, originários de determinados lugares, apresentavam qualidades particulares, atribuíveis à sua origem geográfica. A partir disso, passaram a denominá-los com o nome geográfico de procedência, como, por exemplo, o queijo originário da região de Roquefort, na França, o presunto de Parma, na Itália, e o azeite de oliva Montes de Toledo, na Espanha (VALENTE et al., 2012).

Pimentel $(2009$, p. 33) salienta que "essa noção de indicação geográfica surgiu de forma gradativa, quando produtores e consumidores passaram a perceber os sabores ou qualidades particulares de alguns produtos que provinham de determinados locais". Desde a Grécia Antiga, as cidades procuravam adotar mecanismos que garantissem a origem dos seus produtos, revelando sua qualidade de forma intrínseca, como é o caso dos vinhos de Corinto e da Ilha de Tasso. Para esse produto, havia selos ou símbolos nas ânforas próprias para cada região produtora, com a inscrição do nome do local e do produtor ou respectivos símbolos. Registros do século 7 a.C. comprovam que os gregos já identificavam os melhores vinhos com as respectivas denominações geográficas (GLASS e CASTRO, 2008).

Esse mecanismo de indicações de procedência foi adotado posteriormente pelo Império Romano e estendido a outros produtos, como as tâmaras do Egito, o presunto de Gália, as ostras de Brindisi e o mármore de Carrara (BERTOZZI, 1995). Posteriormente, diversas outras regiões seguiram os mesmos passos, criando mecanismos de proteção para seus produtos com o intuito de combater as falsificações, valorizando suas características e qualidade.

Ao longo do tempo, construiu-se, na Europa, a tradição e a reputação dos produtos com origem reconhecida. O país que mais se destaca historicamente na regulamentação técnica e legal das IGs é a França, principalmente com relação à proteção de seus produtos lácteos e dos vinhos (SOUZA, 2006). O país sediou o primeiro texto jurídico sobre denominação de origem, elaborado pelo Parlamento de Toulose no ano de 1666, que se aplicava à produção regional de queijos (VALENTE et al., 2012).

Contudo, o primeiro registro de IG a ser legalmente reconhecido e delimitado foi feito na região do Douro, em Portugal, em 1756, com a criação da Companhia Geral da Agricultura das Vinhas do Alto Douro, reivindicada pelos produtores de vinho ao Marquês de Pombal, uma vez que vinhos de outras regiões estavam utilizando tal dominação devido à sua notoriedade internacional (BRUCH, 2009).

Em 1855, com a organização dos produtores de vinho franceses em associações, surgiram as primeiras delimitações de território, que acabaram culminando na classificação dos vinhos crus de Bordeaux, um marco no reconhecimento e na valorização da origem dos produtos em âmbito internacional (INAO, 2005).

$\mathrm{Na}$ Alemanha, as primeiras leis referentes às IGs datam de 1874 e tratam sobre a diferenciação entre indicação de origem e marca comercial, e também sobre a necessidade de proteção (KRÜCKEN-PEREIRA, 2001).

$\mathrm{Na}$ América Latina, alguns países também têm feito esforços para garantir a proteção de seus produtos. Produzida desde 1974 em uma determinada região do México, a tequila é um exemplo de denominação de origem protegida por norma oficial mexicana. No Peru, as IGs também possuem grande importância, sendo seu melhor exemplo o pisco, bebida destilada de uva madura, que só é produzida em algumas regiões do país. Na Venezuela, destaca-se o chuao, que, em 2000, foi reconhecido como denominação de origem do cacau originário da região do mesmo nome (GLASS e CASTRO, 2008).

Mais recentemente, é nas economias de nações emergentes, como Índia e China, por exemplo, que se encontra o reconhecimento expressivo de novas indicações, apresentando ao mundo um conjunto de produtos tradicionais, associando 
qualidade e garantia de procedência. Entre outros exemplos de produtos protegidos por IG, destacam-se o óleo de oliva de Aragan e o abacaxi da Guiné na África; os charutos de Cuba; e o café da Colômbia (VALENTE et al., 2012).

\section{I Legislação brasileira da indicação geográfica}

No Brasil, a primeira IG devidamente reconhecida pelo Instituto Nacional de Propriedade Industrial (INPI) foi o Vale dos Vinhedos, em 2002, para vinhos tintos, brancos e espumantes, através da indicação de procedência (INPI, 2013). Atualmente, já somam 14 as indicações geográficas brasileiras registradas no país, sendo: 12 indicações de procedência e duas denominações de origem. Além do Vale dos Vinhedos, já são reconhecidas as indicações de procedência Região do Cerrado Mineiro e Região da Serra da Mantiqueira de Minas Gerais, ambas pela produção de café, Pinto Bandeira (vinhos tintos, brancos e espumantes), Goiabeiras (panela de barro), Pampa Gaúcho da Campanha Meridional (carne bovina e seus derivados), Paraty (cachaça), Pelotas (doces tradicionais de confeitaria e de frutas), Região do Jalapão do Estado do Tocantins (artesanatos em capim dourado), Serro (queijo), Vale do Submédio do São Francisco (manga e uva de mesa) e Vale dos Sinos (couro acabado). Como registro de denominação de origem destaca-se o Litoral Norte Gaúcho (arroz) e a Região da Costa Negra (camarão) (GIESBRECHT et al., 2011). Segundo os autores Glass e Castro (2008, p. 13), "fatores como a diversidade cultural brasileira, seu vasto território e suas particularidades sustentam a afirmação de que há inúmeros produtos nacionais com potencial de obter uma IG".

A repressão às falsas indicações de procedência apareceu no Brasil pela primeira vez por meio do Decreto $n^{\circ} 3.346$, de 1887. Outras leis brasileiras também trataram da repressão às falsas indicações geográficas, como é o caso da Lei $\mathrm{n}^{\circ}$ $1.236 / 1904$, o Decreto ${ }^{\circ} 24.507 / 1934$, o Decreto $\mathrm{n}^{\circ} 7.903 / 1945$ e, finalmente, a Lei ${ }^{\circ}$ 9.279/1996, tendo como base a legislação europeia (BRUCH, 2009).

Segundo Porto (2009), com a promulgação da Constituição de 1988, pela primeira vez na história do país, as indicações geográficas tiveram proteção constitucional. Em seu artigo $5^{\circ}$ XXIX, determina-se que a lei assegurará aos autores de inventos industriais privilégio temporário para sua utilização, bem como proteção às criações industriais, à propriedade das marcas, aos nomes de empresas e a outros signos distintivos, tendo em vista o interesse social e o desenvolvimento tecnológico e econômico do país.

O Brasil ainda não possui um sistema de proteção e controle eficiente para as indicações geográficas. Na verdade, apesar de previsto em lei e ter o seu registro normatizado pelo INPI, o país ainda está muito atrás de países como a França, que, em 2005, comemorou o centenário da primeira lei que deu base para a origem e conceito das IGs, denominada Lei sobre Fraudes e Falsificações em Matéria de Produtos ou de Serviços. Nessa legislação, foi dada ao Estado a função de arbitragem (INAO, 2005).

O registro brasileiro de IG foi estabelecido pela Lei de Propriedade Industrial $n^{\circ} 9.279$, de 14 de maio de 1996, nos artigos de 176 a 182, visando o cumprimento de um dos acordos internacionais que o Brasil assumiu no âmbito da OMC, o acordo Trips. Esse acordo classifica as indicações geográficas em duas importantes espécies, a indicação de procedência (IP) e a denominação de origem (DO), dando ao INPI a competência para estabelecer as condições de concessão e registro das indicações geográficas (INPI, 2013).

Como órgão responsável pelo registro e reconhecimento das IGs no Brasil, o INPI compreende, em suas atividades, além do registro, a identificação de potenciais objetos de proteção, visando à descoberta e à valorização dos produtos regionais brasileiros, além da definição das condições para a concessão das IGs. O registro visa uma maior visibilidade para as regiões produtoras e um maior reconhecimento do produto, por sua qualidade, como diferencial competitivo (GIESBRECHT et al., 2011).

Portanto, a importância da criação de um instituto de IG veio, entre outras razões, da necessidade de proteger os produtores ou prestadores de serviço de determinadas regiões que se tornaram conhecidas pela fabricação de determinados produtos ou prestação de serviços. Os consumidores, igualmente, precisavam se proteger contra as falsas indicações geográficas, no que resultava em concorrência desleal (PORTO, 2009).

As indicações geográficas vêm ganhando reconhecimento e força no Brasil. Esse reconhecimento surge tanto dos consumidores, que cada vez mais estão interessados na qualidade do que consomem, quanto dos produtores. Alguns produtores brasileiros de café, de queijo e de vinhos, principalmente, já reconhecem a importância das IGs como forte ferramenta de mercado e de 
valorização econômica de seus produtos (PORTO, 2009). Segundo o INPI, nos artigos 177 e $178 \mathrm{da}$ Lei ${ }^{\circ}$ 9.279/1996, há um detalhamento a respeito das definições com relação às IGs:

Artigo 177: considera-se indicação de procedência o nome geográfico de país, cidade, região ou localidade de seu território, que se tenha tornado conhecido como centro de extração, produção ou fabricação de determinado produto ou de prestação de determinado serviço.

Artigo 178: considera-se denominação de origem o nome geográfico de país, cidade, região ou localidade de seu território, que designe produto ou serviço cujas qualidades ou características se devam exclusiva ou essencialmente ao meio geográfico, incluídos fatores naturais e humanos.

As denominações de origem (DO) vinculam-se às regiões especializadas na produção e elaboração de determinados produtos, os quais apresentam características (geográficas, meteorológicas e humanas) semelhantes, seja na forma de fazê-los, produzi-los ou coletá-los, sendo uma forma eficaz de identificação e garantia de qualidade de determinado produto, elaborado num território com características específicas e homogêneas e, principalmente, fortalecendo uma relação de confiança entre o consumidor e o produtor e o seu local de produção (CALDAS et al., 2005).

Para Brito (2004, p. 9), "considera-se denominação de origem o nome geográfico de país, cidade, região ou localidade de seu território, que designe produto ou serviço cujas qualidades ou características se devam exclusiva ou essencialmente ao meio geográfico, incluídos fatores naturais e humanos", revelando a ligação existente entre o produto e seu local de origem.

Já a indicação de procedência (IP) valoriza a tradição produtiva e o reconhecimento público de que o produto de uma determinada região possui uma qualidade diferenciada. $\mathrm{Ou}$ seja, é caracterizada por ser área conhecida pela produção, extração ou fabricação de determinado produto, protegendo a relação entre o produto e sua reputação, em razão de sua origem geográfica específica (GIESBRECHT et al., 2011).

Para o reconhecimento de uma IP, não há a necessidade de comprovação da qualidade ou a existência de características peculiares àquela região, sejam elas geográficas, sejam humanas. No entanto, a região precisa ser conhecida como centro de extração, produção ou prestação de um determinado produto ou serviço. A exigência de qualidade que realmente existe é uma exigência mercadológica, originada pelo mercado consumidor e não pela lei (PORTO, 2009).

Portanto, a IP tem como função designar o território ou lugar em que o produto correspondente foi produzido, fabricado, extraído, cultivado etc., sem que este possua determinada característica ou qualidade. Nada mais é do que uma informação ao consumidor sobre a procedência do produto, aplicada a quaisquer produtos de um local geográfico (ALBISINNI, 2000).

Segundo Caldas et al. (2005, p. 11), "as IPs são um instrumento de organização local da produção e as DOs são um instrumento de organização qualitativa do processo de produção" e se diferem, principalmente, pela singularidade e qualidade da produção. Apesar de ambas as espécies terem essencialmente os mesmos objetivos centrais, os dois conceitos apresentam diferenças nítidas. As indicações de procedência permitem associar a qualidade do produto à região onde foi produzido, e as denominações de origem permitem associar o produto às tradições culturais.

Em suma, a indicação de procedência é uma expressão ou sinal utilizado para indicar que um produto ou serviço origina-se em um país, região ou lugar específico. Também, fixa embargos às importações dos países-membros que comercializarem um produto propagando em seu rótulo uma IP enganosa (CHADDAD, 1996).

No Brasil, o INPI estabeleceu as condições para o devido registro das indicações geográficas através da Resolução $n^{\circ} 75 / 2000$, em que apontou, também, outras necessidades legais para o pedido de reconhecimento, como a existência de um órgão na entidade requerente, o Conselho Regulador. Esse conselho realizará suas funções mediante o "Regulamento da Indicação Geográfica", tendo a obrigação de gerir, de manter e de preservar as atividades ligadas à IG em questão (GLASS \& CASTRO, 2008). Conforme o Art. $5^{\circ}$ da resolução, podem requerer registro de IGs, na qualidade de substitutos processuais, as associações, os institutos e as pessoas jurídicas representativas da coletividade legitimada, sendo possível, ainda, que um único produtor ou prestador de serviço esteja legitimado a requerer o uso exclusivo do nome geográfico, se estabelecidos no respectivo território.

O pedido de registro de IG deve conter uma série de documentos que visem caracterizar o produto, o processo produtivo, a área da indicação, 
bem como o sistema de controle do uso da denominação em questão. Além disso, são necessários documentos que comprovem a legitimidade dos requerentes e dos produtores, e o pagamento de retribuições cujo valor depende da espécie de IG pretendida (indicação de procedência ou denominação de origem) (VALENTE et al., 2012).

A primeira IG do país a ser reconhecida foi a IP do Vale dos Vinhedos, localizado na Serra do estado do Rio Grande do Sul, para vinhos tintos, brancos e espumantes. O registro ocorreu em 19 de novembro de 2002, sob o número IG200002 (VALENTE et al., 2012). A Serra Gaúcha é reconhecida, atualmente, como a mais tradicional região produtora de vinhos do Brasil e tem sido apontada como um caso de sucesso em termos da constituição de uma dinâmica de desenvolvimento localizada (territorial, endógena, regional). A reputação construída na região deve-se à associação entre a produção e o empreendedorismo de descendentes de imigrantes italianos que, desde o final do século XIX, construíram na região um sistema peculiar de produção, baseado em saberes, tradições e costumes produzidos e compartilhados ao longo de diversas gerações, além de particularidades naturais referentes ao ambiente. Portanto, trata-se do reconhecimento de um processo evolucionário em que inovações e tradições se mesclaram para formar um produto típico identificado com uma comunidade humana e com o espaço que esta ocupa (NIEDERLE, 2009).

\subsection{Regulamentação da indicação geográfica na União Europeia}

O primeiro marco jurídico internacional a tratar sobre Denominação de Origem Controlada (DOC) foi oficializado em 1883, na França, em meio à Convenção de Paris, por seis países. Atualmente, por meio dessa convenção, resultaram documentos acordados por 160 países, figurando o Brasil entre eles desde 1975 (INPI, 2013).

Os princípios básicos estabelecidos pela Convenção de Paris são apenas dois: o tratamento nacional e o prazo de prioridade. Esses princípios permitiam ao estrangeiro, chegando a outro país, não se atrapalhar com a legislação local sobre propriedade intelectual e, se ela nem existir, poder se orientar pelos princípios básicos estabelecidos pela convenção.

Após três anos, em 1886, na Convenção de Berna, na Suíça, foram determinados padrões mínimos de proteção de obras literárias e artísticas, estabelecendo o reconhecimento do direito de autor entre nações soberanas. Antes da sua adoção, as nações frequentemente recusavam reconhecer os direitos de autor de trabalhos de estrangeiros. Desde 1967, a Convenção é administrada pela World Intellectual Property Organization (WIPO) e, atualmente, quase todas as nações signatárias são membros da OMC, pelo qual o acordo nos aspetos comerciais da propriedade intelectual requer que os não membros aceitem quase todas as condições da Convenção de Berna. Em abril de 2012, eram 165 os países signatários da convenção (WIPO, 2013).

Na tentativa de coibir indicações geográficas fraudulentas, o Sistema de Madri, de registro internacional de marcas, firmou dois tratados: o Acordo de Madri, estabelecendo critérios para o registro de marcas em âmbito internacional, que data de 1891, no qual o Brasil é signatário desde 1911, aderindo, exclusivamente, ao que se refere às indicações de procedência; e o protocolo que está relacionado ao Acordo de Madri, vigente desde 1996. O sistema é administrado pelo departamento internacional WIPO em Genebra, Suíça.

O Acordo de Lisboa foi criado em 1958 e surgiu, justamente, da necessidade de se alcançar, em nível internacional, uma proteção mais eficaz da Denominação de Origem Controlada (DOC). Esse termo difere do anterior, estabelecido pela Convenção de Paris, pois estabelece fronteiras para a sua aplicação e trata sobre o processamento e a qualidade do produto. $\mathrm{O}$ acordo reconhece a estreita ligação entre os atributos de qualidade do produto e as especificidades da sua região de origem cuja qualidade e características devem-se, essencialmente, ao ambiente geográfico, incluindo-se fatores humanos e naturais (CHADDAD, 1996).

Apesar dos acordos e convenções relativos à proteção internacional das IGs, a maioria dos países não adota uma legislação de proteção efetiva. Dessa forma, os dispositivos de regulação são ineficazes para coibir a comercialização de produtos fraudulentos. Ainda, para essa insuficiência de proteção no plano internacional, muito tem contribuído o fato de os acordos internacionais vigentes tratarem dessa questão com a adequação que hoje se impõe, principalmente no contexto globalizado (INPI, 2013).

A proteção jurídica cabível à IG no plano empírico das negociações internacionais ainda se desenvolve com base em acordos bilaterais, e a partir de produtos específicos, em virtude, especialmente, das diferentes concepções de IG entre países (REIS, 2008). Em caso de conflitos 
comerciais, o acordo Trips encaminha-os para a OMC, ou seja, para o âmbito multilateral.

Nesse sentido, a proteção jurídica dessas indicações objetiva o regulamento do uso de nomes, ou marcas de produtos, ou serviços, relacionados especificamente à região em que estes são produzidos ou oferecidos, ou ainda à qualidade resultante essencialmente do fato de serem produzidos nessas regiões (LOCATELLI, 2006).

Pela longa tradição, há muitas décadas as indicações geográficas se destacam em países por toda a Europa. Entre eles, o país de maior cultura no estabelecimento e regulamentação das denominações de origem e suas variações é a França, que conta com um sistema de indicações geográficas de expressiva importância econômica, cultural, sociológica e ambiental, que é considerado parte do patrimônio nacional (CHADDAD, 1996).

Com a organização dos vinicultores franceses em associações, no ano de 1855 , surgiram as primeiras delimitações de território no país, que acabaram culminando na classificação de vinhos crus de Bordeaux, um marco no reconhecimento e na valorização da origem dos produtos (INAO, 2005).

Em 1935, um decreto do governo francês criou o sistema jurídico de Appellation d'Origine Contrôlée (AOC) e o Institut National des Appellations d'Origine (Inao). O instituto criado reuniu funções administrativas, jurídicas e profissionais necessárias para a criação de um sistema de proteção e de controle das indicações geográficas, com apoio e proteção governamental. O AOC é o mais antigo selo oficial de qualidade francês, visando garantir a procedência de produtos alimentícios, sobretudo do vinho (BRABET e PALLET, 2005).

Os produtos com AOC são ricos pela experiência do passado e são únicos devido à sua estreita relação com suas regiões de origem; por isso, alcançaram grande reputação e sucesso comercial no mercado internacional (CHADDAD, 1996). Atualmente, existem na França 455 apelações de origem controlada registradas no Inao, das quais 364 correspondem a bebidas alcoólicas e 49 são produtos lácteos (VALENTE et al., 2012).

No entanto, somente a partir de 1970 a classificação do território como um sistema de denominações de origem foi incentivada e bastante desenvolvida na Europa, quando a União Europeia decidiu difundir um sistema de qualificação e etiquetação de seus territórios, relacionando o produto ao território produtor e aos produtores responsáveis pelo processo de elaboração, identificados por características semelhantes utilizadas em seus processos de produção (CALDAS et al., 2005).

O exemplo mais clássico de um sistema de denominação de origem é aquele que diz respeito ao mundo dos vinhos. A União Europeia é a maior produtora de vinhos de qualidade do mundo. [...] São exemplos os vinhos produzidos sob o sistema de denominações de origem: aqueles do Porto e de Dão (Portugal), de Bordeaux, Provença e da Champanhe (França - Appelation D'origine Controlée), de La Rioja, Riberadel Douro, Ribeiro (Espanha - Denominación de Origen), do Sarre, da Mosela e Fraken (Alemanha - Gebiet), da Sicilia, Puglia, Toscana (Itália - denominazione controllata), etc. (CALDAS et al., 2005, p. 12).

$\mathrm{Na}$ atualidade, a indicação geográfica é um elemento de grande importância na distinção, identificação e valorização de diversos produtos; portanto, sua proteção jurídica se faz fundamentalmente necessária. Existem diversos regulamentos na União Europeia sobre as indicações geográficas, a seguir apresentados.

O Regulamento $n^{\circ} 2.081 / 1992$ da Comunidade Europeia (CE), de 14 de julho de 1992, trata da proteção das indicações geográficas de produtos agrícolas e alimentícios, instaurando um sistema de proteção dos nomes geográficos que comportam duas noções: a Denominação de Origem Protegida (DOP) e a Indicação Geográfica Protegida (IGP) (CONSELHO DA UNIẪO EUROPEIA, 1992). Esse regulamento foi posteriormente modificado pelo Regulamento (CE) $n^{\circ} 510 / 2006$, de 20 de março de 2006.

No Regulamento (CE) no $510 / 2006$, as definições atuais relacionadas às DOPs e IGPs na União Europeia são definidas pelo Artigo $2^{\circ}$ do regulamento, que estabelece, entre outras, que, para efeitos de clareza e de transparência, há que se revogar o Regulamento (CE) $n^{\circ} 2.081 / 1992$ e substituí-lo pelo presente. Essa regulamentação objetivou favorecer a diversificação da produção agrícola, promover produtos característicos, melhorar o rendimento dos agricultores e fixar a população rural na sua zona (CONSELHO DA UNIÃO EUROPEIA, 2006).

O Regulamento (CE) no 510/2006 especifica duas espécies de proteção para produtos agrícolas e gêneros alimentícios: a denominação de origem, que designa a denominação de um produto cuja produção, transformação e elabora- 
ção têm lugar numa área geográfica determinada, com um saber-fazer reconhecido e constatado; e a indicação geográfica, que designa a denominação de um produto com um laço de reputação com um determinado território, pelo menos em um dos estágios da produção, transformação ou elaboração.

O Regulamento (CE) no 2.082/1992, de 14 de julho de 1992, relativo aos certificados de especificidade dos produtos agrícolas e gêneros alimentícios, foi modificado pelo Regulamento (CE) $n^{\circ} 509 / 2006$, em 20 de março de 2006, pois este esclarece que a menção "especialidade tradicional garantida" foi determinada posteriormente ao Regulamento (CE) n ${ }^{\circ}$ 2.082/1992 (CONSELHO DA UNIÃO EUROPEIA, 2006).

Conforme o Regulamento (CE) n ${ }^{\circ} 509 / 2006$, os certificados de especificidade, mais frequentemente designados por "especialidades tradicionais garantidas", permitem satisfazer a procura pelos consumidores de produtos tradicionais com características específicas (CONSELHO DA UNIÃO EUROPEIA, 2006). Perante a diversidade dos produtos colocados no mercado e a quantidade de informações sobre eles fornecidas, o consumidor deverá, a fim de poder efetuar melhor a sua escolha, dispor de informações claras e sucintas que o esclareçam com rigor sobre tais características (BRABET \& PALLET, 2005).

Em 15 de janeiro de 2008, o Parlamento Europeu e o Conselho da União Europeia aprovaram o Regulamento $n^{\circ} 110 / 2008$, relativo à definição, designação, apresentação, rotulagem e proteção das indicações geográficas das bebidas espirituosas, ou seja, bebidas alcoólicas (CONSELHO DA UNIÃO EUROPEIA, 2008).

Finalmente, o mais recente regulamento aprovado pela União Europeia (UE), o Regulamento $\mathrm{n}^{\circ} 1.151 / 2012$, de 21 de novembro de 2012, refere-se aos regimes de qualidade dos produtos agrícolas e dos gêneros alimentícios, e tem por objetivo ajudar os produtores a comunicar, aos compradores e consumidores, as características e os atributos ligados ao modo de obtenção desses produtos e gêneros alimentícios, garantindo, assim: (a) as condições de concorrência leal para os agricultores e produtores de produtos agrícolas e de gêneros alimentícios com características e atributos que ofereçam uma mais-valia; (b) a disponibilização aos consumidores de informações fiáveis sobre esses produtos; (c) o respeito pelos direitos de propriedade intelectual; e (d) a integridade do mercado interno. As medidas previstas nesse regulamento destinam-se a apoiar as atividades agrícolas e de transformação, e os sistemas agrí- colas associados a produtos de elevada qualidade, contribuindo, dessa forma, para a realização dos objetivos da política de desenvolvimento rural (CONSELHO DA UNIÃO EUROPEIA, 2012).

\section{CONSIDERAÇÕES FINAIS}

As IGs trazem contribuições extremamente positivas para as economias locais e para o dinamismo regional, proporcionando o real significado de criação de valor local, atuando como uma espécie de certificação com atributos definidos, garantindo seu enquadramento às normas pré-estabelecidas.

A herança cultural, anteriormente passada de geração em geração, é garantida pelo registro de inovação intelectual concedido pelo INPI. Dessa forma, ter o selo de indicação geográfica assegura a autenticidade dos produtos fabricados de forma artesanal e, também, garante a perpetuação do legado histórico, cultural e tradicional das particularidades do produto e da região. Assim, proteger os produtos de determinada região significa proteger a tradição, a marca, a identidade e o local onde é produzido o produto.

Através deste estudo, pôde-se perceber que as preocupações com Indicações Geográficas são mais antigas nos países da União Europeia e que a legislação europeia traz uma forte regulamentação sobre o assunto. No Brasil, essa visão trazida pela indicação geográfica ainda é muito recente e caminha para uma maior valorização e regulamentação dos produtos dessa natureza.

\section{REFERÊNCIAS}

ALBISINNI, F. L'origine dei prodottiagro-alimentari e laqualitàterritoriale. RivistadiDirittoAgrario, Milano, anno LXXIX, fasc. 1, p. 23-44, genn./mar. 2000.

BERTOZZI, L. Designations of origin: quality and specification. Food Quality and Preferences, v. 6, p. 143-147, 1995.

BRABET, C.; PALLET, D. Os selos oficiais de qualidade dos alimentos na França e na Europa. In: SEBRAE. Valorização de produtos com diferencial de qualidade e identidade: indicações geográficas e certificações para competitividade nos negócios. Brasília: Sebrae, 2005. p. 19-38. 
BRASIL. Lei 9.279, de 14 de maio de 1996. Regula direitos e obrigações relativos à propriedade industrial. Diário Oficial[da] República Federativa do Brasil, Brasília, DF, 15 maio 1996.

BRITO, M. C. de S. Legislação sobre propriedade intelectual. Lei ${ }^{\circ}$. 9.279, de 14 de maio de 1996. Rio de Janeiro: Renovar, 2004.

BRUCH, K. L. Tradição e cultura preservadas: indicações geográficas são meio para assegurar reconhecimento aos diferenciais de uma região produtora. Jornal Bon Vivant, Flores da Cunha: Século Novo, p. 12, jan./fev. 2009.

CALDAS, A. S.; CERQUEIRA, P. S.; PERIN, T. F. Mais além dos arranjos produtivos locais: as indicações geográficas protegidas como unidades de desenvolvimento local. Revista de DesenvolvimentoEconômico, Salvador, n. 11, p. 5-15, 2005.

\section{CONSELHO DA UNIÃO EUROPEIA. Regula-} mento (CE) no 509/2006, de 20 de março de 2006, relativo às especialidades tradicionais garantidas dos produtos agrícolas e dos gêneros. 2006a. Disponível em: <http://eurlex.europa.eu/Notice. do?val $=424452:$ cs\&lang $=$ pt\&list $=484052:$ cs, 4435 94:cs, $442695: \mathrm{cs}, 440777: \mathrm{cs}, 424452: \mathrm{cs}, 419156: \mathrm{cs}, 4$ $18695: \mathrm{cs}, 396247: \mathrm{cs}, 393579: \mathrm{cs}, 392645: \mathrm{:s}, \&$ pos $=5$ \&page $=1 \&$ nbl $=81 \&$ pgs $=10 \&$ hwords $=$ \& checktext $\mathrm{e}=$ checkbox\&visu=\#texte $>$. Acesso em: 3 abr. 2013.

CONSELHO DA UNIÃO EUROPEIA. Regulamento (CE) no 510/2006, de 20 de março de 2006, relativo à proteção das indicações geográficas $\mathrm{e}$ denominações de origem dos produtos agrícolas e dos gêneros alimentícios. 2006b. Disponível em: $<$ http://eur-lex.europa.eu/LexUriServ/LexUriServ. do?uri=CELEX:32006R0510:pt:NOT>. Acesso em: 3 abr. 2013.

CONSELHO DA UNIÃO EUROPEIA. Regulamento (CE) no 110/2008, de 15 de janeiro de 2008, relativo à definição, designação, apresentação, rotulagem e proteção das indicações geográficas das bebidas espirituosas e que revoga o Regulamento (CE) no 1576/1989 do Conselho. Disponível em: $<$ http://eur-lex.europa.eu/LexUriServ/LexUriServ.do?uri =OJ:L:2008:039:0016:0054:PT:PDF $>$. Acesso em: 4 abr. 2013.

CONVENÇÃODA UNIÃO DE PARIS PARA PROTEÇÃO DA PROPRIEDADE INDUSTRIAL. Convenções de Paris, 1883. Bruxelas, 1900. Brasília:
INPI, 1975. Disponível em: <http://www.inpi.gov. $\mathrm{br} /$ images/stories/CUP.pdf $>$. Acesso em 24 jan. 2013.

GIESBRECHT, H. O.; SCHWANKE, F. H.; MÜSSNICH, A. G. Indicações geográficas brasileiras: braziliangeographicalindications/indicaciones geográficas brasileñas. Brasília: Sebrae, INPI, 2011. $164 \mathrm{p}$.

GIL, A. C. N. Técnicas de pesquisa em economia. São Paulo: Atlas, 2002.

GLASS, R. F; CASTRO, A. M. G. As indicações geográficas como estratégia mercadológica para vinhos. Organizações Rurais \& Agroindustriais, Lavras, v. 10, n. 2, p. 189-202, 2008.

GOLLO, S. S. Inovação e estratégia de cooperação competitiva: estudo de caso da indicação de procedência Vale dos Vinhedos, Serra Gaúcha/RS. 2006. 359 f. Tese (Doutorado em Administração)-Universidade Federal do Rio Grande do Sul, Porto Alegre, 2006.

INAO. Le goût de l'origine. [Paris]: Hachette, 2005.

INPI. INSTITUTO NACIONAL DE PROPRIEDADE INDUSTRIAL. Guia básico - indicação geográfica. 2013. Disponível em: <http://www.inpi. gov.br/portal/artigo/guia_basico_indicacao_geografica>. Acesso em: 24 jan. 2013.

INPI. INSTITUTO NACIONAL DA PROPRIEDADE INDUSTRIAL. Resolução ${ }^{\circ} 75$ INPI, de 28 de novembro de 2000. Estabelece as condições para o registro das indicações geográficas. 2000. Disponível em: <http://www.camelier.com.br/legislacao/ legislacao-indicacao-geografica/34/resolucao-inpino-0752000.html> Acesso em: 10 fev. 2013.

KAKUTA, S. M. et al. Indicações geográficas: guia de respostas. Porto Alegre: Sebrae/RS, 2006.

KRÜCKEN-PEREIRA, L. O processo de valorização de produtos alimentícios através das denominações de origem e qualidade: uma abordagem de gestão do conhecimento. 2001. 167 f. Dissertação (Mestrado em Engenharia de Produção) $\square$ Universidade Federal de Santa Catarina, Florianópolis, 2001.

LOCATELLI, L. Indicações geográficas e desenvolvimento econômico. In: BARRAL, W.; PIMENTEL, L. O. (Org.). Propriedade intelectual e desenvolvi- 
mento. Florianópolis: Fundação Boiteux, 2006.

NGOKKUEN, C.; GROTE, U. Geographical indication for Jasmine Rice: applying a logit model to predict adoption behavior of Thai Farm Households. QuarterlyJournalofInternationalAgriculture, v. 51, n. 2, p. 157-185, 2012.

NIEDERLE, P. A. Controvérsias sobre a noção de indicações geográficas enquanto instrumento de desenvolvimento territorial: a experiência do Vale dos Vinhedos em questão. In: CONGRESSO BRASILEIRO DE ECONOMIA E SOCIOLOGIA RURAL, 47, 2009, Porto Alegre. Anais eletrônicos... Rio Branco: Sober, 2009. Apresentação oral. Disponível em: <http://www.sober.org.br/palestra/13/35. pdf>. Acesso em: 10 fev. 2013.

OMC. ORGANIZAÇÃO MUNDIAL DO COMÉRCIO. Acordo sobre aspectos dos direitos de propriedade intelectual relacionados ao comércio (Acordo TRIPS ou Acordo ADPIC). Diário Oficial da União, Brasília, DF, 31 dez.1994. Número 248-A, Seção 1, p. 93-103.

PIMENTEL, L. O. (Org.). Curso de propriedade intelectual e inovação no agronegócio. Módulo II, Indicação Geográfica. Brasília: Mapa; Florianópolis: EaD/UFSC, 2009. p. 33.

PORTO, P. C. R. Indicações geográficas, modelo Brasil. Evocati Revista, Aracaju, n. 29, maio 2009. Disponível em: <http://www.evocati.com. $\mathrm{br} /$ evocati/interna.wsp?tmp_page=interna\&tmp codigo $=228 \&$ tmp_secao $=14 \& \mathrm{tmp}$

topico=direitocomercial>. Acessoem: 5 fev. 2013.

REIS, L. L. M. Indicação de procedência: uma nova dimensão da competitividade para o território da APAEB-Valente. 2008. 206 f. Dissertação (Mestrado em Desenvolvimento Regional e Urbano)-Universidade Salvador, Salvador, 2008.

SAMPIERI, R. H.; COLLADO, C. F.; LUCIO, P. B. Metodologia de Pesquisa. 3. ed. São Paulo: McGraw-Hill, 2006.

SOUZA, M. C. M. Cafés sustentáveis e denominação de origem: a certificação de qualidade na diferenciação de cafés orgânicos, sombreados e solidários. 2006. 177 f. Tese (Doutorado em Ciência Ambiental)-Faculdade de Economia, Administração e Contabilidade, Universidade de São Paulo, São Paulo, 2006.
VALENTE, M. E. et al. Indicação Geográfica de alimentos e bebidas no Brasil e na União Europeia. Ciência Rural, Santa Maria, v. 42, n. 3, p. 551-558, mar. 2012.

WIPO. WORLD INTELLECTUAL PROPERTY ORGANIZATION. What is intellectual property? 2013. Disponívelem: < http://www.wipo.int/about-ip/en/>. Acesso em: 25 jan. 2013. 